\title{
Nonlinear approximation of wildfire front temperature on MODIS data for sub-pixel analysis of burning
}

\author{
Kirill Yu. Litvintsev ${ }^{1}$, Evgenii I. Ponomarev ${ }^{2,3}$ and Evgenii G. Shvetsov ${ }^{2}$ \\ ${ }^{1}$ S.S. Kutateladze Institute of Thermophysics SB RAS, Novosibirsk, Russia \\ ${ }^{2}$ V.N. Sukachev Institute of Forest, Federal Research Center "Krasnoyarsk Science Center SB RAS", Krasnoyarsk, Russia \\ ${ }^{3}$ Siberian Federal University, Krasnoyarsk, Russia
}

\begin{abstract}
An improved approach to evaluate thermal anomalies characteristics using the pixel-based analysis of the MODIS imagery was proposed. The approach allows us to improve the accuracy in estimating characteristics of active combustion zones comparing to the standard Dozier method. We used the imagery of active wildfires in Siberian forests from the MODIS radiometer acquired in the spectral ranges of 3.930-3.990 and 10.780-11.280 $\mu \mathrm{m}$ (bands 21 and 31, respectively). Nonlinear exponential function was used to describe the approximation of the temperature of combustion zones. Available data of field and numerical experiments were used for validating of the approximation accuracy. Nonlinear approximation of wildfire front temperature allows to determine the portion of the active pixel of the MODIS image with the given temperature excess comparing to the temperature of background cover. This improves the accuracy in extracting of active burning zones as well as in classifying the heat release rate at the sub-pixel level of analysis.
\end{abstract}

\section{Keywords}

Remote data, active combustion zone, wildfire, radiation, sub-pixel analysis.

\section{Introduction}

Detection of vegetation fires and instrumental estimation of combustion characteristics is one of most important directions of the thematic analysis of remote sensing data [1,2]. The resolution of specialized satellite systems used in fire monitoring as a rule does not exceed $250 \mathrm{~m}$, and the best known Russian platforms of forest fire monitoring ("ISDM" of the Federal Forestry Agency and "Kaskad" of the Russian Ministry of Emergency Situations) handle satellite information with a spatial resolution of $1000 \mathrm{~m}$, which, at present, determines a limited set of available attributive parameters of fires - coordinates, area, and time. Early detection of wildfires is significantly limited because their characteristics can be detected only when carrying out the subpixel analysis based on reliable models of the integral signal formation in the image pixel including the small-size source of thermal anomaly. Theoretically [3], satellite methods allow us to discover a hot spot with an area of $100 \mathrm{~m}^{2}$; in practice, according to estimates, the probability of detection a hot spot with an area of 5000 to $6000 \mathrm{~m}^{2}$ and temperature of $700 \mathrm{~K}$ is $60-70 \%$ [4].

SDM-2021: All-Russian conference, August 24-27, 2021, Novosibirsk, Russia $\bigoplus$ sttupick@yandex.ru (K. Yu. Litvintsev); evg@ksc.krasn.ru (E.I. Ponomarev)

(c) (1) $\odot 2021$ Copyright for this paper by its authors. Use permitted under Creative Commons License Attribution 4.0 International (CC BY 4.0).

CEUR Workshop Proceedings (CEUR-WS.org) 
Development of new approaches for the effective estimation of hot spot parameters at different stages of fire growth remains a topical problem [5, 6, 7]. At present, only a few works are available regarding recording and processing data on the energy characteristics of thermally active zones in case of fires in boreal forests $[8,9,10]$, although the method was tested many times on the example of experimental fires with known characteristics $[5,11]$. Therefore, development of methods for instrumental quantitative estimates of fire characteristics is at present not a completely solved problem in spite of the fact that works in this direction have been carried out since the second half of the $20^{\text {th }}$ century $[12,13,14]$.

In this work, we consider the problem of approximating the temperature distribution of the active combustion front to improve the classification of thermally active zones at the subpixel level and estimating the heat release rate at different fire phases. Based on the numerical calculations, the effectiveness of the nonlinear distribution function in interpreting MODIS (Moderate Resolution Imaging Spectroradiometer) imagery data for the determination of fire characteristics is analyzed. The main goal of the work is to improve the method of the subpixel analysis of MODIS data. Our objectives were to: (1) approximate the temperature profile of the active combustion zone perpendicularly to the fire front propagation direction and (2) to compare the effectiveness of the subpixel detection of thermal anomalies based on the proposed and standard [13] approaches.

\section{Description of the nonlinear approximation and initial data}

This work involves the field data collected on vegetation fires in Siberia according to the results of processing the MODIS imagery during the period from 2003 to 2018 [15].

In addition, standard MODIS products of the $\mathrm{L} 2 \mathrm{G}$ and $\mathrm{L} 3$ processing levels were analyzed. Pixel data on radiometric temperature in the ranges $\lambda=3.93-3.99$ (radiometer band 21) and 10.78$11.28 \mu \mathrm{m}$ (band 31) were calculated from the MOD11A1 product [16]. The radiative power of active combustion zones were determined from MOD14/MYD14 Collection 6 products [17]. From the MODIS thermal anomaly products we obtained fire radiative power (FRP) characterizing the thermal emission power and combustion rate $[11,18]$. Using the bispectral method [13] we performed subpixel analysis for the MODIS active fire pixels. The characteristics of the fire front were additionally refined based on Sentinel-2 imagery.

Based on the obtained and processed satellite data, the effectiveness of the determination of the energetic and geometric characteristics of fires was analyzed. At the first stage, pixels corresponding to the wildfires were identified; then, the active subpixel portion allowing us to estimate the areas and rates of the active combustion zone was determined. For this purpose, the bispectral method [13] was used. It estimates the characteristics of active fire zone in a MODIS pixel based on the values of the averaged temperature of the target and background. The solution is based on analyzing the rate of radiation of the active combustion zone. The rate is determined for the wavelength in the IR range $\lambda_{1}$ and $\lambda_{2}$ :

$$
\begin{gathered}
\left\{\begin{array}{c}
L_{\lambda 1}=\alpha \cdot L\left(\lambda_{1}, T_{m}\right)+(1-\alpha) \cdot L_{\lambda 1}^{0}, \\
L_{\lambda 2}=\alpha \cdot L\left(\lambda_{2}, T_{m}\right)+(1-\alpha) \cdot L_{\lambda 2}^{0},
\end{array}\right. \\
L(\lambda, T)=\frac{c_{1}}{\lambda^{5} \cdot\left(e^{\frac{c_{2}}{\lambda \cdot T}}-1\right)},
\end{gathered}
$$


where $L(\lambda, T)$ is the Planck formula for the radiance, $\mathrm{W} /\left(\mathrm{m}^{3} \times \mathrm{sr}\right) ; \alpha$ is the portion of the active zone in the pixel; $L_{\lambda 1}$ and $L_{\lambda 2}$ are the radiation rates recorded in the ranges $\lambda_{1}$ and $\lambda_{2} ; L_{\lambda 1}^{0}$ and $L_{\lambda 2}^{0}$ are the background radiation rates in the given ranges, respectively; $T_{m}$ is the averaged temperature of the active combustion zone; $c_{1}=1.19 \times 10^{-16} \mathrm{~W} \times \mathrm{m}^{2}, c_{2}=14.388 \times 10^{-2} \mathrm{~m} \times \mathrm{K}$.

The main assumption of the bispectral method [13] is the uniform distribution of the surface temperature in the active combustion zone (Figure 1). This can lead to a significant error in calculations of the fire area because the temperature distribution profile is not uniform. In this work, the temperature profile was approximated by nonlinear exponential function (Figure 1):

$$
T\left(y, T_{\max }\right)=\left(T_{\max }-T_{0}\right) \cdot\left[\left(\frac{n_{1}}{n_{2}}\right)^{\frac{n_{1}}{n_{2}}} \cdot e^{-\frac{n_{1}}{n_{2}}}\right]^{-1} \cdot\left(\frac{y}{L}\right)^{n_{1}} \cdot e^{-\frac{(y) n_{2}}{L^{n_{2}}}}+T_{0}, \quad L>0,
$$

where the parameters $n_{1}$ and $n_{2}$ are responsible for the steepness of the front edge of the active fire zone and uniformity of the temperature profile, respectively; $T_{\max }$ is the maximum temperature, $T_{0}$ is the background temperature; $L>0$ is the parameter characterizing the linear width of the active zone front, $\mathrm{m}$; and $y\left(T=T_{\max }\right)=-\sqrt[n_{2}]{\frac{n_{1}}{n_{2}}} \cdot L$ is the coordinate of the temperature maximum. When using this approximation, it is assumed that the width of the fire front is significantly less than its length. In this case, with allowance for (2), Eq. (1) is modified as follows:

$$
\begin{gathered}
\left\{\begin{array}{c}
L_{\lambda 1}=\alpha \cdot \bar{I}\left(\lambda_{1}, T_{\max }\right)+(1-\alpha) \cdot I_{\lambda 1}^{0}, \\
L_{\lambda 2}=\alpha \cdot \bar{I}\left(\lambda_{2}, T_{\max }\right)+(1-\alpha) \cdot L_{\lambda 2}^{0},
\end{array}\right. \\
L\left(\lambda, T_{\max }\right)=\frac{1}{y_{2}-y_{1}} \cdot \int_{y_{1}}^{y_{2}} \frac{1.19 \cdot 10^{-16}}{\lambda^{5} \cdot\left(e^{\frac{1.44 \cdot 10^{-2}}{\lambda \cdot T\left(y, T_{\max }\right)}}-1\right)} d y,
\end{gathered}
$$

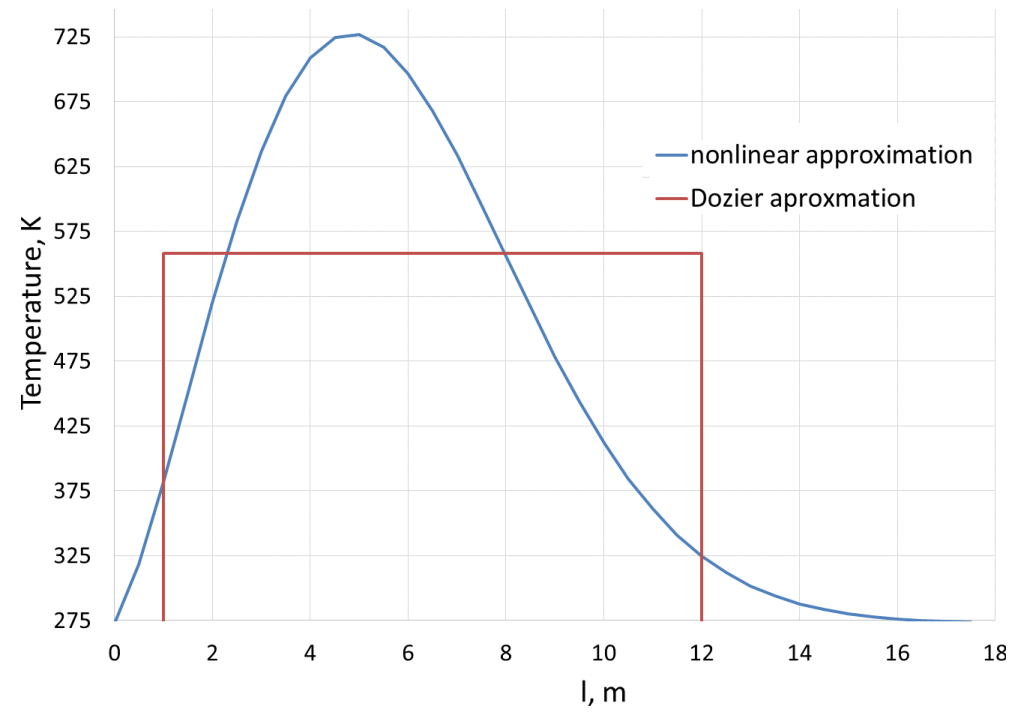

Figure 1: General form of the surface temperature approximation in the region of an active subpixel according to [13] and using a nonlinear exponential function perpendicularly to the fire front propagation. 
where $y_{1}=0$ and $y_{2}=3 L$. In the case where $y_{1}$ and $y_{2}$ are linear functions of $L$, the value $\bar{I}$ does not depend on $L$.

Values of the parameters $n_{1}=1.3$ and $n_{2}=2$ were obtained based on the generalization of experimental data for fires in Siberia [19]. Following the results of the generalization, model temperature curves were obtained (Figure 2). In general, the proposed approximation of temperature allows us to sufficiently closely reproduce the temperature profile of the fire front. This approximation ignores low-rate combustion/smoldering regions, which are observed as a rule behind the fire front (Figure 2).

In the solution of the system of equations (3), the magnitude of the active portion of pixel $\alpha$, in contrast to the standard method [13], in fact does not determine the combustion region but characterizes the subpixel region with a temperature exceeding the background temperature. To determine the portion of the pixel with a given excess of the temperature $\Delta T_{a}$ over the background, it is necessary to find roots of Eq. (5) $y_{\alpha 1}$ and $y_{\alpha 2}$ in the interval $\left(y_{1} ; y_{2}\right)$ :

$$
\left(T_{\max }-T_{0}\right) \cdot\left[\left(\frac{n_{1}}{n_{2}}\right)^{\frac{n_{1}}{n_{2}}} \cdot e^{-\frac{n_{1}}{n_{2}}}\right]^{-1} \cdot\left(\frac{y}{L}\right)^{n_{1}} \cdot e^{-\frac{(y)^{n_{2}}}{L^{n_{2}}}}-\Delta T_{a}=0 .
$$

After the calculation of $y_{\alpha 1}$ and $y_{\alpha 2}$ the portion of the region $\alpha_{a}$ with the given $\Delta T_{a}$ is determined as follows:

$$
\alpha_{a}=\alpha \cdot \frac{\left|y_{\alpha 2}-y_{\alpha 1}\right|}{3 L} .
$$

The ratio of active pixel portions calculated by Dozier's method $\left(\alpha_{D}\right)$ and modified bispectral method $\left(\alpha_{a}\right)$ with the temperature excess over the background $\Delta T_{a}$ is determined as:

$$
A_{\Delta T}=\frac{\alpha_{a}}{\alpha_{D}} .
$$

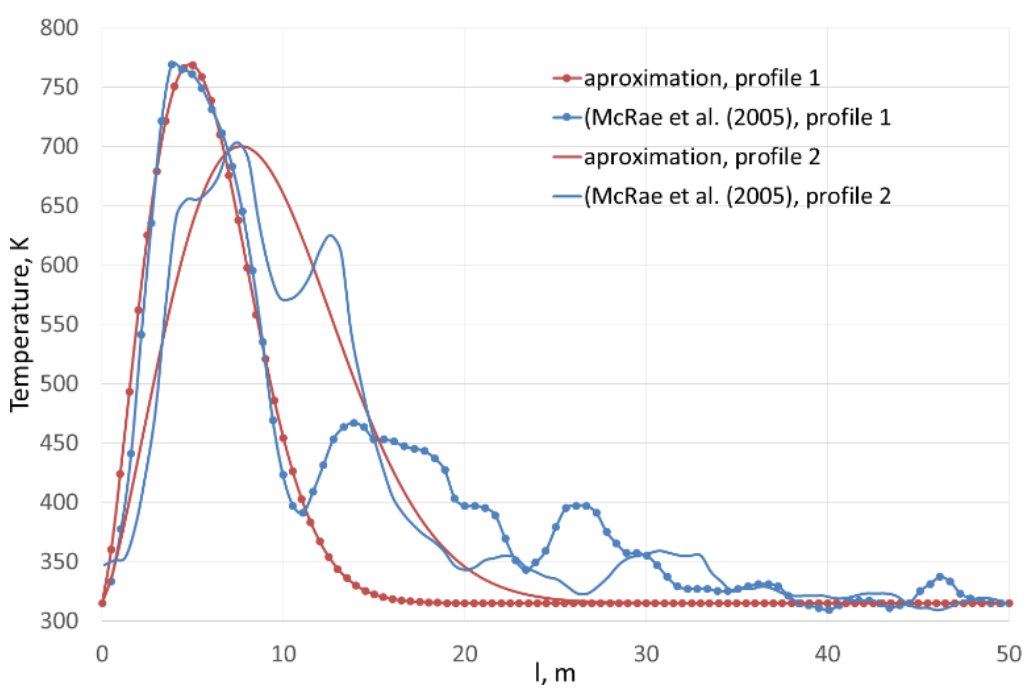

Figure 2: Surface temperature distribution: field measurement data [19] and their nonlinear approximations. The extreme values of the temperature measurement data correspond to the fire front and residual spots of combustion and smoldering behind the fire front. 
To verify the proposed nonlinear approximation, available data of field measurements and numerical simulations of the temperature distribution on the surface during a surface fire were considered.

To evaluate the effectiveness of the proposed approach, the comparative analysis of the subpixel characteristics (temperature and area of the active combustion zone) and results of the standard bispectral method [13] was carried out. It involved a sample of pixels from MODIS images containing more than 23000 hot spots. The considered image pixels corresponded to fires detected in Krasnoyarsk Angara Region (mainly, fires in pine forest stands), Evenkiya region (fires in larch forests), and the left bank of the Yenisei River.

The power of fire radiation from a unit area of the active combustion zone was estimated using the standard bispectral method [13] and the method with the nonlinear approximation of temperature with the use of different threshold excesses of the temperature to extract the active combustion zone. This sample contained 9500 MODIS fire pixels. For each pixel, values of the fire's radiative power (FRP) were determined and sub- pixel areas of the high-temperature zone were calculated using the considered methods. Calculation of the areas by the proposed modified method involved the following values of threshold temperatures for the determination of the active combustion zone: $50,100,160$, and $200{ }^{\circ} \mathrm{C}$. The fire radiative power from a unit area was calculated as the ratio of the total heat release power of a fire pixel to the area of the high-temperature zone.

\section{Results and discussion}

The spatial resolution of satellite systems does not allow us to directly obtain the fire data of this kind with the required accuracy. So, below, the fire front's temperature profiles (Figure 2) approximated based on field measurements [19] are used as a calibration of satellite acquisition materials.

To verify the nonlinear approximations were compared with field measurement data obtained by low speed wind tunnel at Riverside Fire Laboratory [20] (Figure 3, a) and with numerical simulation results of a fire spread through a grassland [21], (Figure 3, b). Coefficients $n_{1}$ and $n_{2}$ in

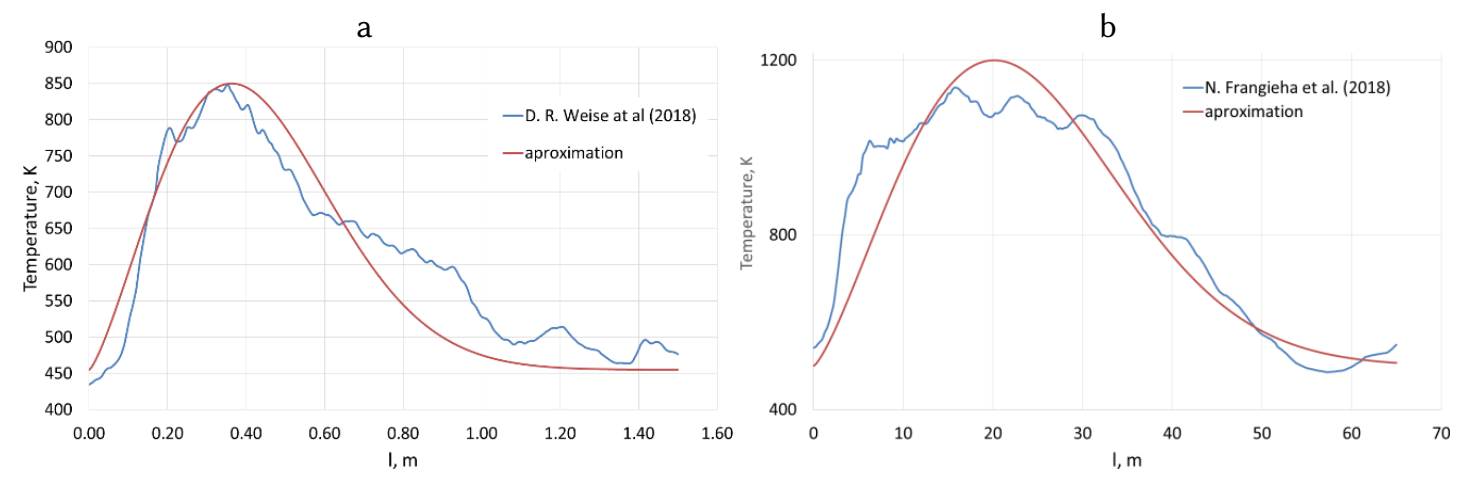

Figure 3: Surface temperature distribution: a - field measurement data [20] and its nonlinear approximations; $b$ - numerical simulation data [21] and its nonlinear approximations. 
Table 1

Characteristics of variation in temperature and area of the active zone for the used test sample of pixels corresponding to the active fire phase.

\begin{tabular}{c|cc|ccccc}
\hline \multirow{2}{*}{$\begin{array}{c}\text { MODIS } \\
\text { band }\end{array}$} & \multicolumn{2}{|c|}{ T, K } & \multicolumn{5}{c}{ Temperature variation over the sample $(T, \mathrm{~K})$} \\
& average & $\sigma$ & median & $\min$ & $\max$ & percentile 10 & percentile 90 \\
\hline 21 & 326.9 & 20.4 & 321.3 & 305.0 & 502.3 & 309.4 & 351.0 \\
31 & 294.6 & 6.3 & 295.2 & 271.2 & 400.1 & 286.7 & 301.6 \\
$21^{*}$ & 298.7 & 6.9 & 300.4 & 276.3 & 320.0 & 288.8 & 306.7 \\
$31^{*}$ & 291.9 & 5.9 & 292.7 & 268.3 & 306.7 & 283.9 & 298.9 \\
\cline { 2 - 8 } & \multicolumn{2}{|c|}{$S, \mathrm{~km}^{2}$} & \multicolumn{6}{|c}{ Variation in the active zone area over the sample $\left(S, \mathrm{~km}^{2}\right)$} \\
\cline { 2 - 7 } & 1.9 & 1.4 & 1.3 & 1.0 & 9.7 & 1.0 & 3.5 \\
\hline
\end{tabular}

* Measurements of background values.

the equation (2) not were changed. The data from $[20,21]$ in Figure 3 is the surface temperature profile averaged along the fire front. Despite the different scales of the considered fires and different fuel beds (pine needles [20] and grass [21]), the nonlinear approximation describes their temperature profiles well enough.

The statistical characteristics of active fire zone parameters (data of the MODIS bands 21 and 31) recorded for the test sample are presented in Table 1. Since the subpixel analysis used in this work is applicable only for surface fires, the table presents characteristics of fire pixels with the exception of the maximum temperatures (above the $90^{\text {th }}$ percentile). This excluded the portion of pixels that corresponded with a high degree of probability to the crown fire phase that we do not deal with [10].

The obtained data did not take into account the influence of the scanning angle on the estimate of the area of the ground projection of the MODIS pixel because the error is not accumulated when the calculation results obtained for the subpixel analysis based on the considered approaches are compared. At the same time, it is known that the area of the pixel projection increases with an increase in the scanning angle (deviation from nadir). This, in the general case, leads to a decrease in the fraction of the area occupied by the fire bed within the limits of the pixel and, therefore, to a decrease in the contrast between the fire pixel and background in the thermal IR range. Due to the comparison of the two approaches, this uncertainty in fact had no effect on the results of the comparative analysis. In spite of the fact that the sample was not limited in the maximum scanning angle, the deviation from nadir for the main part (68\%) of MODIS pixels used in the analysis was within 300 and their area did not exceed $1.7 \mathrm{~km}^{2}$. The average area amounted to about $1.9 \mathrm{~km}^{2}$.

The quantitative analysis of the processed fire pixels for which the portion of the active subpixel was determined using the method [13] and modified bispectral method with a threshold excess of the temperature over the background $\Delta T_{a}$ demonstrates that the main part of the coincidence falls on values $\Delta T_{a}$ in the interval from 60 to $160{ }^{\circ} \mathrm{C}$. Up to $15 \%$ of the pixels were detected outside the above-mentioned range (Figure 4). We can say that the concept of the active pixel portion has no clear definition when the standard method [13] is used because there is in fact no given referencing to the energy characteristics of the fire. The high-temperature region 


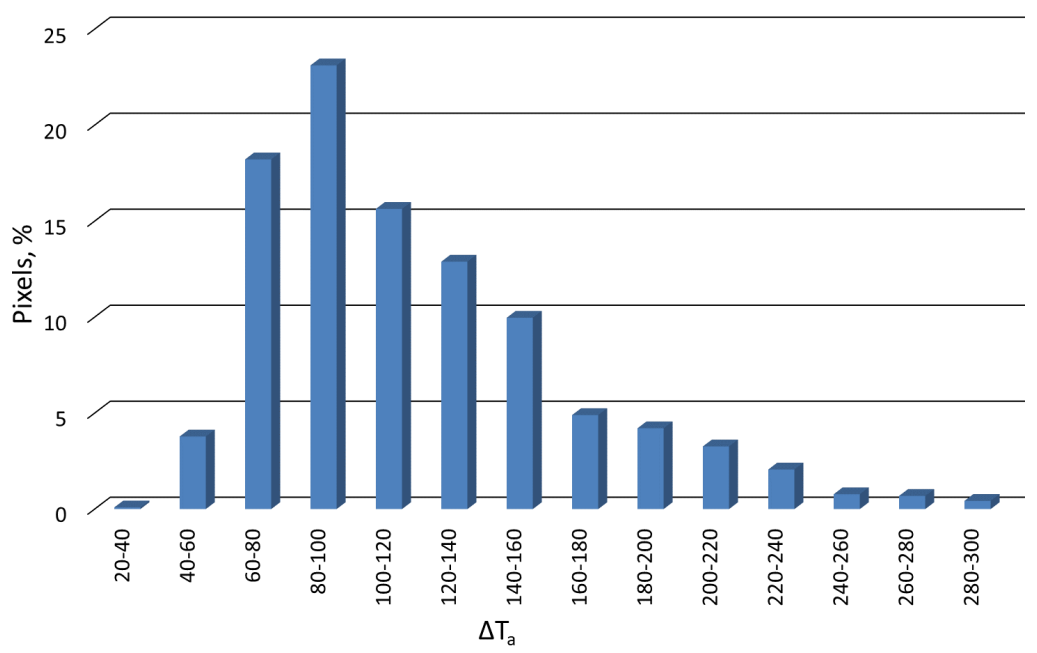

Figure 4: Distribution of pixels over intervals $\Delta T_{a}\left({ }^{\circ} \mathrm{C}\right)$ for which portions of active subpixels calculated by the standard (Dozier, 1981) and modified methods coincide.

which is taken into account in this method depends on the calculated average temperature determined to a considerable extent by the fire's intensity.

Figure 5 shows the dependence of the ratio $A_{\Delta T}$ (see (7)) on the averaged temperature for different $\Delta T_{a}$ in the modified method. In particular, for $\Delta T_{a}=60^{\circ} \mathrm{C}$, the coincidence of the methods is observed in the interval of averaged temperatures of 420 to $450^{\circ} \mathrm{C}$; for $\Delta T_{a}=140{ }^{\circ} \mathrm{C}$, in the interval of 600 to $630^{\circ} \mathrm{C}$. For example, if we assume that an active subpixel is characterized by temperature exceeding the background values by $60^{\circ} \mathrm{C}$, the difference between the results of the two methods reaches $40 \%$ (Figure 5). In general, the overestimation of the active pixel portion

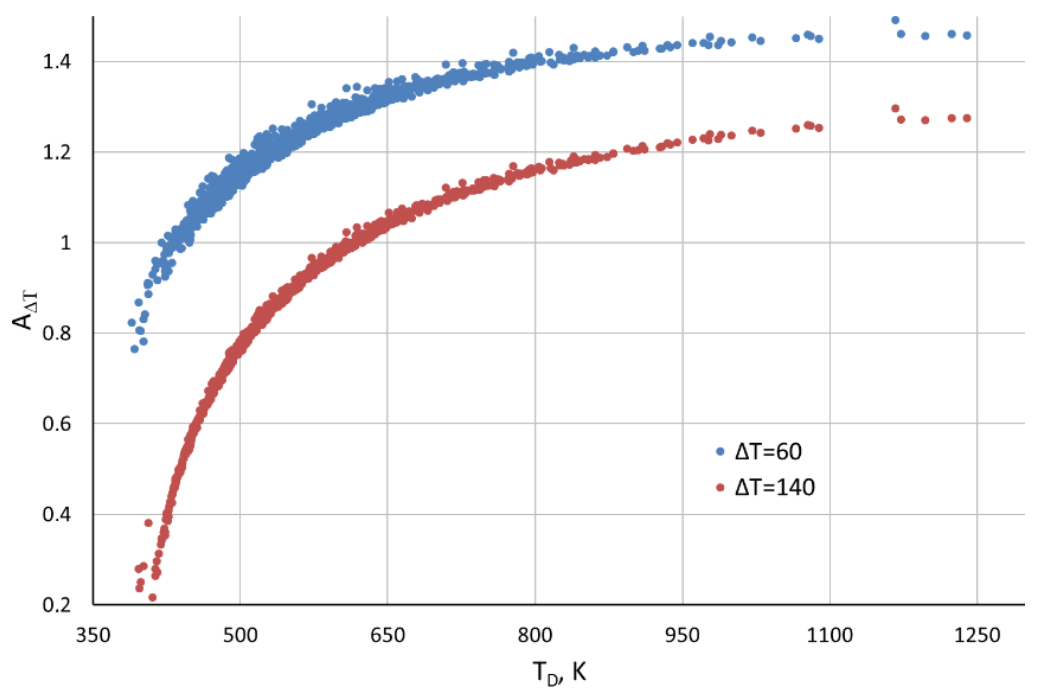

Figure 5: Relationship of pixel portions when using the nonlinear and standard approximations of temperature in the active combustion region for the bispectral method. $\Delta T_{a}$ is equal to 60 and $140{ }^{\circ} \mathrm{C}$. 


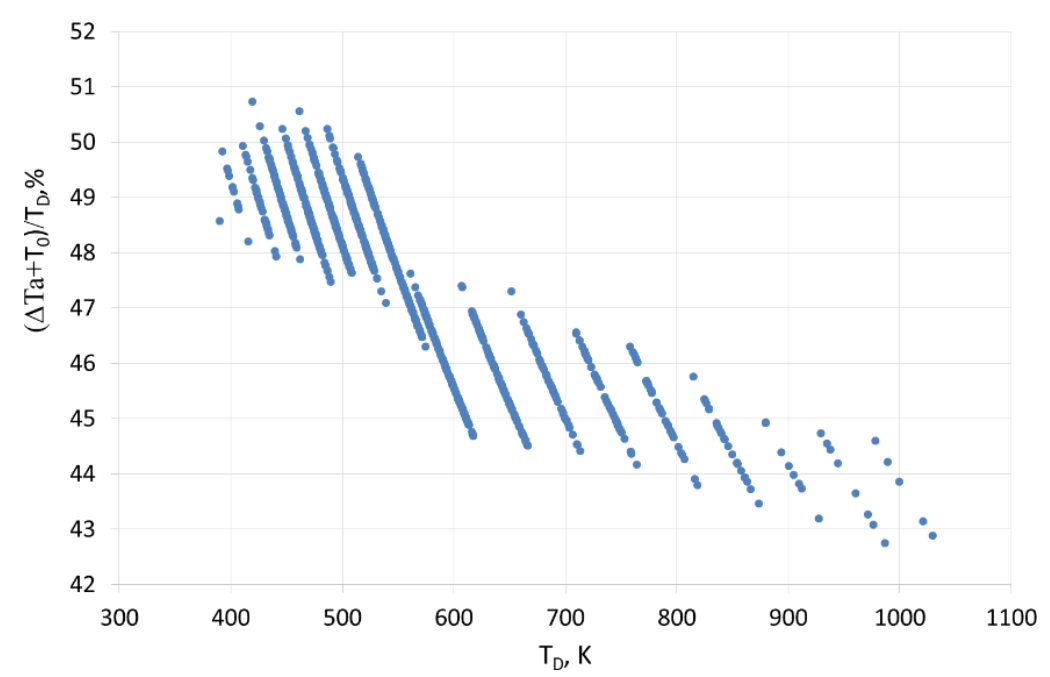

Figure 6: Ratio of the threshold temperature to the averaged temperature calculated by the method of [13] as a function of the fire intensity, the background temperature $T_{0}$ equals $300 \mathrm{~K}$ (the linear structure of the distribution is related to the interval-by-interval approximation of temperature).

in the standard approach is inversely proportional to the variation of the parameter $\Delta T_{a}$.

If we consider the dependence of the ratio of $\Delta T_{a}$ (when $\alpha_{a}\left(\Delta T_{a}\right) \approx \alpha_{D}$ ) to the averaged temperature $T_{D}$, then this quantity varies with a relatively small range from 0.4 to 0.5 . Therefore, based on the given $T_{\max }$ for the modified method, we can calculate $\Delta T_{a}$ for which the condition $\alpha_{a}\left(\Delta T_{a}\right) \approx \alpha_{D}$ is satisfied; i.e., the active subpixel portion is close to that calculated by the method of [13] (Figure 6). The nonlinear approximation of temperature, as noted above, is more effective because it is physically closer to the real temperature distribution on the surface of the active zone than the approximation used in the standard approach.

Another important problem related to the nonuniformity of the temperature distribution is the determination of $\Delta T_{a}$ for the active portion of the fire pixel. We can use two approaches: specifying the $\Delta T_{a}$ and calculating $\Delta T_{a}$ from the condition of falling within the temperature range above $T_{0}+\Delta T_{a}$, providing more than $95 \%$ of the radiation energy of the considered range of $\lambda$. For example, when using the second approach with $T_{\max }$ of about $720^{\circ} \mathrm{C}, \Delta T_{a}=235{ }^{\circ} \mathrm{C}$; at $T_{\max }=450{ }^{\circ} \mathrm{C}, \Delta T_{a}$ is only $64^{\circ} \mathrm{C}$.

The results of the performed analysis demonstrate that the representation of the fire region as a region with a uniform temperature can lead to a significant error when estimating the active zone area at the subpixel level and intensity of the acting fire front. In particular, it is seen from the dependences presented in Figure 1 that the area of the active zone for the uniform approximation corresponds to an excess of about $60{ }^{\circ} \mathrm{C}$ over the background temperature compared to the nonlinear approximation; the averaged temperature here is lower than the maximum temperature approximately by $170{ }^{\circ} \mathrm{C}$. These deviations vary depending on the recorded values of the radiation intensity. Therefore, the uniform distribution in each case determines the active zone area with an unknown temperature which cuts off the lowtemperature region. Using a nonuniform approximation of the temperature distribution on the surface for the active combustion zone, in contrast to a uniform approximation, allows us to 
separate regions with different levels of the given temperatures, e.g., the region of high-intensity combustion.

The major part of the considered fire pixels was characterized by the fire's radiative power values of up to $10 \mathrm{~kW} / \mathrm{m}^{2}$ (about $80 \%$ for larch forests of Evenkiya and about $65 \%$ for pine forests of the Angara Region). It has been found that, for the fire pixel sample used in the analysis, the subpixel area obtained by the standard bispectral method corresponds to the results obtained according to the method considered in this paper at the threshold temperatures of 120 to $140{ }^{\circ} \mathrm{C}$. At lower threshold temperatures $\left(50\right.$ and $\left.100^{\circ} \mathrm{C}\right)$, the estimates of the subpixel areas were larger than according to the standard method and, as a consequence, the portion of pixels with low thermal radiation intensity (up to $5 \mathrm{~kW} / \mathrm{m}^{2}$ ) increased. At the same time, the higher values of the temperature threshold $\left(160\right.$ and $\left.200^{\circ} \mathrm{C}\right)$ yielded lower estimates of the sub-pixel area and higher thermal radiation intensities. In particular, at the threshold value of $200{ }^{\circ} \mathrm{C}$, most fire pixels pass to the category of 5 to $10 \mathrm{~kW} / \mathrm{m}^{2}$.

\section{Conclusions}

The effectiveness of the subpixel analysis of the MODIS data based on the bispectral method in the problem of detection and description of thermal anomalies can be increased with the use of the nonlinear approximation of the temperature of the active fire zone. This approximation is shown that it describes quite well the surface temperature profile of the surface fire front propagation for the considered set of field and numerical data. By the example of the proposed nonlinear exponential approximation, it is shown that, in contrast to the standard method, only such an approach allows us to specify the determination of the active pixel portion of the MODIS image either via the excess of temperature in it over the background temperature or via the portion of the radiation energy. The discrepancy in the determination of the active pixel portion when using the considered approaches reaches tens of percent, which has a significant effect on the final classification of the heat release rate at the subpixel level according to the phases of the fire's evolution (e.g., phases recorded remotely in an expeditious manner).

At present, the main problem in using the nonlinear approximation of temperature is the accumulation of the empirical and calculated data on the temperature distribution on the surface in the active combustion zone for different types of natural fires with the aim of refining the proposed approximation function or creating a family of such functions.

\section{Acknowledgments}

This research was partly funded by the Russian Foundation for Basic Research (RFBR) and Government of the Krasnoyarsk krai, and Krasnoyarsk krai Foundation for Research and Development Support, No. 20-44-242002.

\section{References}

[1] Bartalev S.A., Stytsenko F.V., Egorov V.A., Lupyan E.A. Satellite assessment of fire-caused forest mortality in Russia // Lesovedenie. 2015. No. 2. P. 83-94. 
[2] Bondur V.G., Gordo K.A., Kladov V.L. Spacetime distributions of wildfire areas and emissions of carbon-containing gases and aerosols in northern Eurasia according to satellite-monitoring data // Izv. Atmos. Ocean. Phys. 2017. Vol. 53. No. 9. P. 859-874. DOI:10.1134/S0001433817090055.

[3] Justice C.O., Malingreau J.-P., Setzer A.W. Satellite remote sensing of fires: Potential and limitations / P.J. Crutzen, J.G. Goldammer (Eds.). Fire in the Environment: The Ecological, Atmospheric, and Climatic Importance of Vegetation Fires. Berlin, 1992. P. 77-88.

[4] Shvetsov E.G. Probabilistic method for satellite detection and control of energy parameters of wildfires East Siberia // Extended Abstract of Cand. Sci. (Tech.) Dissertation. Krasnoyarsk, 2012.

[5] Ichoku C., Kaufman Y.J. A method to derive smoke emission rates from MODIS fire radiative energy measurements // IEEE Trans. Geosci. Remote Sens. 2005. Vol. 43. P. 2636-2649.

[6] Vermote E., Ellicott E., Dubovik O., Lapyonok T., Chin M., Giglio L., Roberts G.J. An approach to estimate global biomass burning emissions of organic and black carbon from MODIS fire radiative power // J. Geophys. Res. 2009. Vol. 114. D18205. P. 1-22. DOI:10.1029/2008JD011188.

[7] Safronov A.N., Fokeeva E.V., Rakitin V.S., Grechko E.I., Shumsky R.A. Severe wildfires near Moscow, Russia in 2010: Modeling of carbon monoxide pollution and comparisons with observations // Remote Sens. 2015. Vol. 7. No. 1. P. 395-429. DOI:10.3390/rs70100395.

[8] Ponomarev E.I. Classification of Siberian fires in term of FRP-based radiation intensity according to Terra/MODIS data // Issled. Zemli iz Kosmosa. 2014. No. 3. P. 56-64. DOI:10.7868/S0205961414020080.

[9] Shvetsov E.G., Ponomarev E.I. Estimating the influence of external environmental factors on fire radiative power using satellite imagery // Contemporary Probl. of Ecol. 2015. Vol. 8. No. 3. P. 337-343. DOI:10.1134/S1995425515030142.

[10] Ponomarev E.I., Shvetsov E.G., Usataya Yu.O. Determination of the energy properties of wildfires in Siberia by remote sensing // Izv. Atmos. Ocean. Phys. 2018. Vol. 54. No. 9. P. 979-985. DOI:10.1134/S000143381809030X.

[11] Wooster M.J., Roberts G., Perry G.L.W., Kaufman Y.J. Retrieval of biomass combustion rates and totals from fire radiative power observations: FRP derivation and calibration relationships between biomass consumption and fire radiative energy release // J. Geophys. Res. 2005. Vol. 110. D24311. DOI:10.1029/2005JD006318.

[12] Byram G.M. Combustion of forest fuels // Forest Fire: Control and Use. New York: McGrawHill, 1959. P. 61-89.

[13] Dozier J. A method for satellite identification of surface temperature fields of sub-pixel resolution // Remote Sens. Environ. 1981. Vol. 11. P. 221-229.

[14] Matson M., Dozier J. Identification of subresolution high temperature sources using a thermal IR sensor // Photogram. Eng. Remote Sens. 1981. Vol. 47. No. 9. P. 1311-1318.

[15] Ponomarev E.I., Shvetsov E.G. Satellite detection of forest fires and geoinformation methods of data calibration // Issled. Zemli Kosmosa. 2015. No. 1. P. 84-91. DOI:10.7868/S0205961415010054.

[16] Wan Z., Hook S., Hulley G. MOD11A1 MODIS/Terra Land Surface Temperature/Emissivity Daily L3 Global 1km SIN Grid V006 (Dataset) // NASA EOSDIS LP DAAC, 2015. DOI:10.5067/MODIS/MOD11A1.006. 
[17] Giglio L., Schroeder W., Justice C.O. The collection 6 MODIS active fire detection algorithm and fire products // Remote Sens. Environ. 2016. Vol. 178. P. 31-41.

[18] Kumar S.S., Roy D.P., Boschetti L., Kremens R. Exploiting the power law distribution properties of satellite fire radiative power retrievals: A method to estimate fire radiative energy and biomass burned from sparse satellite observations // J. Geophys. Res. 2011. Vol. 116. D19303. DOI:10.1029/2011JD015676.

[19] McRae D.J., Jin J.-Z., Conard S.G., Sukhinin A.I., Ivanova G.A., Blake T.W., Infrared characterization of fine-scale variability in behavior of boreal forest fires // Can. J. For. Res. 2005. Vol. 35. No. 9. P. 2194-2206.

[20] Weise D.R., Johnson T.J., Hao W.M., Princevac M., Scharko N., Oeck A., Myers T.L., Baker S., Lincoln E., Aminfar A.H. Measurement of pyrolysis products from mixed fuel beds during fires in a wind tunnel // Advances in Forest Fire Research. 2018. P. 534-541. DOI:10.14195/978-989-26-16-506_59.

[21] Frangieha N., Morvana D., Meradjib S., Accaryc G., Bessonov O. Numerical simulation implicit physical multiphase model // Fire Safety Journal. 2018. Vol. 102. P. 37-47. 